\title{
Swine Flu (Influenza A H1N1 2009) infection in pregnancy- a profile of cases at a large tertiary centre in Dubai
}

\author{
Tasneem Rangwala, Mary John, Muna Tahlak \\ Department of Obstetrics and Gynaecology, Al Wasl Maternity and Paediatric Hospital, Dubai, UAE
}

\section{A B STRACT}

During the H1N1 -2009 Influenza A pandemic, 96 pregnant and postpartum women confirmed positive by nasopharyngeal swab polymerase chain reaction were managed at AI Wasl Hospital, a tertiary referral centre in Dubai between 3rd august to 17th December 2009.we studied the characteristics, immediate outcome and complications of these cases. Majority presented with high fever, headache and one or more respiratory symptoms. They were managed according to WHO guidelines. $49 \%$ women needed hospitalisation. Most had mild illness and recovered completely. One case had severe illness needing ICU admission, culminating in maternal death. We conclude that the effect of swine flu in our cohort was mild. Co morbidity and delay in seeking treatment led to worsening disease .Vaccination with Pandemrix (single dose vaccine) is recommended for all pregnant women and their health providers if there is onset of a new wave of infection.

Key words: H1N1 influenza, pregnancy, maternal morbidity.

\section{INTRODUCTION}

The H1N1 influenza A (2009) pandemic affected most countries of the world and 3287 confirmed cases have been reported from Dubai emirate with 7 deaths (Dubai Health Authority information-Personal communication). UAE has large number of visitors and expatriate population that includes pregnant women. According to observations from past seasonal influenza epidemics, pregnant women are at increased risk of severe disease and influenza related hospital admissions ${ }^{1}$. Since the outbreak, our centre has managed a large number of pregnant women with H1N1 influenza A (2009) infection in the region. Our aim was to study the characteristics of women presenting with H1N1 influenza A (2009), their immediate outcome and complications.

\footnotetext{
Address for correspondence: Dr. Tasneem Rangwala Department of Obstetrics and Gynaecology Al Wasl Hospital, Dubai, UAE, PO Box- 9115 TEL: 009714-2193926

E-mail: drtasneem.rangwala@gmail.com/drtasneem@hotmail.com
}

DOI: 10.5530/ijmedph.4.2011.3

\section{METHODS}

Al Wasl maternity and paediatric hospital is a large tertiary referral centre in UAE for northern emirates with a delivery rate of $7000 /$ year. It has a 24 -hour walk-in clinic attached to Obs/Gyn emergency that serves patients presenting via self-referral, peripheral health centres and private hospitals. Our study included a cohort of pregnant and postpartum women presenting between 3rd august and 17th December 2009 with fever and acute respiratory illness and confirmed positive for H1N1 influenza A (2009) by nasopharyngeal swab polymerase chain reaction (PCR). A special laboratory was set up to provide results in 24-48 hours. Emergency and obstetric case records of these women were reviewed to extract demographic and clinical data and entered into a data collection tool in Excel format. Data were analysed and descriptive statistics were used.

All confirmed cases received oseltamivir $75 \mathrm{mg}$ BD orally for 5 days, free of cost from hospital pharmacy. Additional antibiotics were prescribed where bacterial infection was suspected. Cases with severe respiratory illness were started with oseltamivir prophylactically before results were available. Zanamivir is not made available in UAE. 
Contacts of confirmed cases were traced and treated in peripheral health centres. WHO guidelines were used in management of cases with special attention to hand hygiene and use of PPE (personal protective equipment) when attending these cases. Cases were admitted according to their clinical condition, (indications being high fever $>38^{\circ} \mathrm{C}$, severe respiratory symptoms $+/-$ co morbidity) in isolation rooms in different wards of the hospital. Clinically stable patients were discharged on oseltamivir and advised to self-isolate at home. They were contacted on phone to discontinue oseltamivir, if PCR result came negative and were advised to return to hospital if there was deterioration in symptoms even after 48 hours of treatment.

\section{RESULTS}

226 pregnant and postpartum women suspected to have swine flu infection were seen in the obstetrics \& Gynaecology unit of Al Wasl hospital between 3rd august to 17 th December 2009 of which 96 cases (42.4\%) were confirmed positive. The characteristics of these women are shown in table 1 . The mean age was 31 years, (range: $18-44$ yrs.) 51\% were local Arabs, 12.5\% other Arabs and $36.5 \%$ were non Arabs. Two- fifths of women (40\%) were nulliparous and rest were multiparous. The mean gestational age at presentation was 22 weeks (range: $6-39$ weeks). 5 cases of $96(5.2 \%)$ were post delivery. $10 \%$ cases gave history of travel and also $10 \%$ gave history of close contact with a positive case of swine flu. 14 cases in our cohort (14.5\%) had co morbidity such as Diabetes mellitus (8 cases), Hypertension (1 case), Gestational diabetes + Hypertension (2 cases), malaria (1 case) and urinary tract infection (2 cases). 93.7\% women presented with high temperature,headache and one or more symptoms of upper respiratory tract infection(cough, rhinorrhoea, sorethroart). Majority $(93.7 \%)$ of cases presented within 2 days of symptom onset. 49\% cases were admitted and 51\% were treated as outpatients. $92.7 \%$ received oseltamivir treatment. 7 cases declined oseltamivir but accepted other treatments for common cold. The interval between symptom onset and start of treatment ranged from 2-3 days. The duration of hospitalisation was 3-5 days (mean: 4 days). Pregnancy complications were seen in 5.2\% cases (Hyper emesis, oligamnios and ante partum haemorrhage). 6 of 7 cases who had refused oseltamivir recovered and 88 cases who received oseltamivir recovered completely but one woman of Indian origin aged 34 yrs., who presented on 9 th post caesarean day with severe illness,
Table 1: Characteristics of pregnant women with Influenza A/ H1N1 2009 infection at Al Wasl Hospital (3rd august17th December 2009)

\begin{tabular}{|c|c|c|}
\hline Characteristic & Frequency(n) & $\%$ \\
\hline \multicolumn{3}{|l|}{ Age in years } \\
\hline $18-25$ & 29 & 30.2 \\
\hline 26- 35 & 58 & 60.4 \\
\hline 36- 45 & 9 & 9.4 \\
\hline \multicolumn{3}{|l|}{ Nationality } \\
\hline UAE Arabs & 49 & 51 \\
\hline Other Arabs & 12 & 12.5 \\
\hline Non Arabs & 35 & 36.5 \\
\hline \multicolumn{3}{|l|}{ Parity } \\
\hline Nulliparous & 38 & 39.6 \\
\hline Multiparous & 58 & 60.4 \\
\hline \multicolumn{3}{|l|}{$\begin{array}{l}\text { Gestational Age at } \\
\text { presentation (weeks) }\end{array}$} \\
\hline 13 & 32 & 33.3 \\
\hline 14-28 & 33 & 34.3 \\
\hline$>28$ & 26 & 27.2 \\
\hline Post partum & 5 & 5.2 \\
\hline History of Travel & 10 & 10.4 \\
\hline No history of travel & 86 & 89.6 \\
\hline History of Contact & 10 & 10.4 \\
\hline No History of Contact & 86 & 89.4 \\
\hline \multicolumn{3}{|l|}{ Co morbidity } \\
\hline Diabetes mellitus & 8 & 8.3 \\
\hline Hypertension & 1 & 1 \\
\hline Malaria & 1 & 1 \\
\hline UTI (urinary tract infection) & 2 & 2 \\
\hline Diabetes + Hypertension & 2 & 2 \\
\hline \multicolumn{3}{|l|}{ Temperature at presentation } \\
\hline$<37.5^{\circ} \mathrm{C}$ & 6 & 6.3 \\
\hline$>37.5^{\circ} \mathrm{C}$ & 90 & 93.7 \\
\hline \multicolumn{3}{|c|}{$\begin{array}{l}\text { Interval between onset of illness } \\
\text { \& presentation }\end{array}$} \\
\hline$<1$ day & 0 & 0 \\
\hline$=<2$ days & 90 & 93.7 \\
\hline$>=3$ days & 6 & 6.3 \\
\hline Admitted to hospital & 47 & 49 \\
\hline Outpatient $R x$ & 49 & 51 \\
\hline Received Anti-viral & 89 & 92.7 \\
\hline Refused Anti-viral & 7 & 7.3 \\
\hline \multicolumn{3}{|c|}{$\begin{array}{l}\text { Interval between onset of illness } \\
\quad \& \text { start of } R x\end{array}$} \\
\hline$<1$ day & 0 & 0 \\
\hline$=<2$ days & 73 & 76.1 \\
\hline$>=3$ days & 16 & 16.6 \\
\hline Refused Rx & 7 & 7.3 \\
\hline \multicolumn{3}{|l|}{ Duration of hospital stay } \\
\hline $1-3$ days & 20 & 42.5 \\
\hline$>=3$ days & 27 & 57.5 \\
\hline Not admitted & 49 & \\
\hline \multicolumn{3}{|l|}{ Pregnancy complications } \\
\hline Hyper emesis & 2 & 2 \\
\hline Oligamnios & 2 & 2 \\
\hline Ante partum Haemorrhage & 1 & 1 \\
\hline \multicolumn{3}{|l|}{ Outcome } \\
\hline Improved without Rx & 11 & 6.3 \\
\hline Improved with Rx & 87 & 91.7 \\
\hline Required ICU admission & 1 & 1 \\
\hline Died & 1 & 1 \\
\hline
\end{tabular}


needed ICU admission and intubation due to respiratory failure. She had Insulin dependent Diabetes mellitus and hypertension. In spite of the best supportive measures she developed multiorgan failure and died subsequently. During the study period all 2nd and 3rd trimester cases were followed up till delivery and none had foetal abnormalities. 1st trimester cases (32 of total 91) were followed according to registry maintained for swine flu cases in our centre. 27 of them delivered at our hospital and none had foetal abnormalities.

\section{DISCUSSION}

As soon as news was received from other countries about swine flu cases, the infection control committee of our hospital and the central infection control committee for DHA (Dubai health authority) took active measures to contain the spread of H1N1 A influenza virus. Keeping in mind the lessons from epidemiological evidence that pregnant women, due to immune-suppression are more prone for complications if they develop influenza and starting anti-viral therapy within 48 hours of symptoms can aid recovery ${ }^{2}$, there were widespread media campaigns to educate public and lectures to educate physicians about the nature and effects of swine flu.

Antiviral drugs are not a cure but reduce the duration of illness, secondary complications and mortality. ${ }^{2}$ commonly used drugs are the neuraminidase inhibitors, oseltamivir (oral) and zanamivir (given by inhalation). In comparison to oseltamivir, zanamivir is effective in respiratory tract but does not reach effective levels systemically . Presently Oseltamivir resistance is rare and no onward transmission of resistant virus has occurred ${ }^{3}$. In spite of explanation of safety, 7 of our cases had declined oseltamivir (1 case was on antimalarial and had excessive vomiting, 2 cases were in first trimester and anxious about fetal anomalies and 4 cases were concerned about drug adverse effects).

WHO guidelines were strictly followed for management of cases. Posters were put in all strategic locations in the hospital and information booklets made available to all women attending hospital. Treatment was given free of cost to all suspected cases. Due to these factors and increased public awareness, panic was minimised and majority of cases $(93.7 \%)$ presented early, within 2 days of symptom onset and treatment was started early leading to complete recovery in all except one case which presented late with severe illness and ended in mortality. In the study published by ML Lim et al in February $2010^{4}$, there were 11 cases of morbidity and no mortality. In a series published by Jamieson and co-workers comprising 34 women from 13 states in USA, there were 10 morbidity and 1 mortality case $\mathrm{C}^{4}$.

It is interesting to note that $63 \%$ cases in our cohort were from Arab population (Table 1). This may be attributable to cultural factors like large family gatherings and greeting by kissing. 5 of 96 cases $(5.2 \%)$ in our cohort developed swine flu infection postpartum. 4 of them showed symptoms on 2 nd postnatal day while in hospital, were discharged on recovery after 2 days of oseltamivir treatment. Oseltamivir was continued during breastfeeding as the drug and its metabolite are excreted in breast milk in very small quantity and unlikely to have clinical sequelae in the infant. Women were reassured about the safety of the drug${ }^{2}$. The 5 th case, who was hypertensive and diabetic on treatment, was discharged on 4th post caesarean day in good general condition, but acquired the infection in community and presented on 9th postnatal day to our emergency with respiratory distress. She was intubated and admitted to ICU and died after 5 days. Breathlessness, a symptom of respiratory complication is a strong predictor for both ICU requirement and death ${ }^{3}$. Mortality in our case confirms the significance of this feature as also the report by Jain and colleagues, in which dyspnoea was more likely to be seen in H1N1 A influenza patients admitted to ICU and in those who died ${ }^{5}$.

\section{CONCLUSION}

The effect of swine flu infection on our cohort was mild due to early diagnosis and initiation of antiviral therapy. Oseltamivir was well tolerated by majority .Co-morbidity and delay in seeking medical help lead to severe illness and mortality. We recommend vaccination with Pandemrix (single dose vaccine with excellent safety profile ${ }^{1}$.) for all pregnant women and their direct health carers if there is a future outbreak of this infection.

\section{ACKNOWLEDGEMENTS}

1. Dr. Mohammed Reza Rahimi and Dr. Fatma Abdalla, Department of preventive medicine, Rashid hospital, Dubai Health Authority - for quick dissemination of results of H1N1 swab PCR.

2. Dr. Ahmed Masfari, Head of Microbiology Department at Rashid Hospital, Dubai Health Authority-for guidance on management of cases.

3. Mrs. Susan Thomas, medical secretary, Department of Obs/Gyn. - for secretarial assistance. 


\section{REFERENCES}

1. Importance of Vaccinating Pregnant Women- Letter from Royal College of Obstetricians And Gynecologists to Nurses and midwives - 27 November 2009 (http://www.rcog.org.uk.Accessed 1 march 2010).

2. Pregnancy, Breastfeeding and Swine Flu A/ H1N1: Department of healthHealthcare-29 may 2009 (http://www.rcog.org.uk.Accessed1 march 2010).
3. Pandemic H1N1 2009 influenza: Clinical Management Guidelines for pregnancy. Prepared by the Department of Health and Royal College Of Obstetricians and Gynecologists.published October 2009, revised 10th December 2009.

4. Lim M, Chang C, Tee W, Chee J. Influenza A/H1N1(2009) infection in pregnancy- an Asian perspective. BJOG 2010;117:551-556.

5. Jain S, Kamimoto L, Bramley AM, Schmitz AM, Benoit SR, Louie J et al. Hospitalized patients with 2009 H1N1 influenza in the United States. April- June 2009. N Eng J Med 2009;361: 1935-44. 